Dynamic Stock Dependence and Monetary Variables in the United States (2000-2016): A Copula and Neural Network Approach

Miriam Sosa, Christian Bucio, and Edgar Ortiz 
Miriam Sosa, Christian Bucio, and Edgar Ortiz

Dynamic Stock Dependence and Monetary Variables in the United States (20002016): A Copula and Neural Network Approach

Abstract: This paper investigates dynamic dependence between the American Stock Market (S\&P 500) and the World Share Market (MSCIW) and examines whether key monetary variables (short and long-term interest rates, interest rate spreads, and exchange rate) explain changes in this relation, during the period January 2000 - June 2016. The methodology includes a Dynamic Copula approach and a Multilayer Perceptron Network. Results suggest that there is interdependence between the American and global stock. market and that the dynamic dependence is mainly explained by the short-term interest rate spread, 3-month T-bill's rate and 3-month London Interbank Offered Rate LIBOR rate.

Keywords: stock market dependence, monetary variables, Copula approach, artificial neural network.

JEL Classification: C45, C58, D53, E49, G15.

Dependencia bursátil dinámica y variables monetarias en Estados Unidos (20002016): estimación vía cópulas y redes neuronales artificiales

Resumen: El objetivo de la presente investigación es analizar la dependencia dinámica entre el indice bursátil americano S \&P 500 y el indice bursátil mundial (MSCIW), así como, examinar si variables monetarias clave (tasas de interés de corto y largo plazo, diferenciales de tasas de interésy tipo de cambio) explican los cambios en dicha relación de dependencia. Elperiodo de estudio es de enero de 2000 a junio de 2016, el cual incluye periodos de calma e incertidumbre. La metodología incluye las metodologias de cópula dinámica y red neuronal perceptrón multicapa. Los resultados sugieren que existe un fenómeno de interdependencia entre los mercados bursátiles. Las variaciones en la relación de dependencia se explican por los cambios en el diferencial de tasas de interés de corto plazo (LIBOR 3 meses - T-bill's 3 meses).

Palabras clave: dependencia bursátil, variables monetarias, metodología Cópula, Redes Neuronales Artificiales. 
Dépendance boursière dynamique et variables monétaires aux États-Unis (20002016) : estimation par copulations et réseaux de neurones artificiels

Résumé: L'objectif de cette recherche est d'analyser la dépendance dynamique entre l'indice boursier américain S\&P 500 et l'indice boursier mondial (MSCIW), ainsi que d'examiner si des variables monétaires clés (taux d'intérêt à court et à long terme, différentiels de taux d'intérêt et taux de change) expliquent les changements dans cette relation de dépendance. La période d'étude s'applique de janvier 2000 à juin 2016, ce qui comprend des périodes de calme et d'incertitude. La méthodologie comprend les méthodologies de la copule dynamique et du réseau de neurones perceptrons multicouches. Les résultats suggèrent qu'il existe un phénomène d'interdépendance entre les marchés boursiers. Les variations $d u$ rapport de dépendance s'expliquent par les variations de l'écart de taux d'intérêt à court terme (LIBOR 3 mois - 3 mois de T-bill).

Mots clés: dépendance boursière, variables monétaires, méthodologie Copule, Réseaux de Neurones Artificiels.

Cómo citar / How to cite this item:

Sosa-Castro, M. M., Bucio-Pacheco, C., \& Ortiz-Caliso, E. (2022). Dynamic Stock Dependence and Monetary Variables in the United States (2000-2016): A Copula and Neural Network Approach. Lecturas de Economía, 96, 201-234.

https://doi.org/10.17533/udea.le.n96a345321 


\title{
Dynamic Stock Dependence and Monetary Variables in the United States (2000-2016): A Copula and Neural Network Approach
}

\author{
Miriam Sosa $\oplus^{a}$, Christian Bucio $\oplus^{b}$, and Edgar Ortiz Calisto $\oplus^{c}$ \\ -Introduction -I. Methodology -II. Empirical Evidence. -Conclusions. -References \\ Original manuscript received on 15 February 2021; final version accepted on 28 August 2021
}

\section{Introduction}

Increased financial globalization and its negative effects have renewed the debate around the incidence of monetary variables in stock markets co-movements. Concurrently, the rising sensitivity of stock markets' comovements due to financial and economic innovations has heightened concerns about identifying which financial variables explain changes in the international dependence on stock markets and financial contagion.

Current financial literature research has acknowledged that monetary variables, such as exchange rate and interest rate, impact financial contagion and dependence. However, most studies have focused on changes on these phenomena during crises periods, particularly during the Great Recession of 2008-2011 and its sequel to the Eurozone and the world markets in general.

Empirical studies have unveiled an important relationship between portfolio investments and monetary variables. During the recent crises (subprime, sovereign debt, global financial, COVID-19) changes in risk free rates triggered important downturns in stock indexes, instability periods and currency depreciations which led to increased levels of dependence and comovements between stock markets. Representative research on this area

a Miriam Sosa: Professor at Universidad Autónoma Metropolitana, México.

E-mail: msosac87@hotmail.com. https://orcid.org/0000-0002-6597-5293

b Christian Bucio: Professor at Universidad Autónoma del Estado de México, México.

E-mail: christianbucio@yahoo.com.mx. https://orcid.org/0000-0002-0860-199X

c Edgar Ortiz Calisto: Professor at Universidad Nacional Autónoma de México, México.

E-mail: edgaro@unam.mx https://orcid.org/0000-0001-5486-2982 
includes those by Chiang, Jeon and Li (2007), Kenourgios et al. (2011), Syllignakis and Kouretas (2011), Cho and Choi (2015), Cevik and Ozturkkal (2020), Glover et al. (2020), Ortmans and Tripier (2020), and Ben Amar et al. (2021). Frequently, those studies have concluded that contagion expands during episodes of extreme economic and financial distress. Moreover, research dealing with co-movements between stock markets have stressed increased correlations.

However, this approach has been criticized. Forbes and Rigobon (2002), Loretan and English (2000), and Boyer et al. (1997) demonstrate that the conventional correlation is biased and inaccurate to model financial relationships because the stylized facts of financial series (such as heteroskedasticity, fat tails, clustered volatility, long memory, and asymmetry). Thus, the correlation coefficient may lead to spurious results (Forbes \& Rigobon, 2002; Baur, 2003).

To overcome this problem, we propose a methodology based on copula theory which yields more consistent estimations about the behavior of financial series. Notably, due to Archimedean copulas properties, several studies have used them to test contagion effect: Rodriguez (2007), Kenourgios et al. (2011), Aloui et al. (2011), Maneejuk and Yamaka (2019), Mohti et al. (2019), to mention a few of them.

Among studies which have analyzed the U.S. stock market relationships employing the copula approach are those developed by Chen et al. (2014), Aloui et al. (2011), Tachibana (2018), and Gong et al. (2020). Chen et al. (2014) examined the contagion effect between the U.S. and Chinese stock markets during the recent financial crisis by combining multifractal volatility and the copula approach. Their evidence suggests that the statistical characteristics of Kendall's $\tau$ during crisis and non-crisis periods are different; the contagion effect increased about $87.39 \%$ on average during a crisis period. Similarly, Aloui et al. (2011) analyzed the conditional dependence structure between the U.S. and BRIC stock markets using a GARCH-Copula approach. They found strong evidence of time-varying dependence between each BRIC market and the U.S. market. Finally, Tachibana (2018) applies a vine copula approach to analyze co-movements between currency and the stock markets 
of 22 countries and the U.S. stock market. Results indicate that both stock and currency markets in these economies are highly correlated with the U.S. stock market during the crisis period of 2007-2012.

More recently, Mohti (2019), applied copula models to examine contagion from the USA subprime financial crisis on a large sample of frontier stock markets before and after the crisis. Kendall's $\tau$ and the Spearman's $\rho$ were used to gauge the presence ${ }^{1}$. Their evidence reveals significant evidence of contagion in the European region, mainly with the markets of Croatia and Romania. Other frontier markets in the sample seemingly remained. Similarly, BenMin and BenSaïda (2019) employ a regular vine copula model to examine dependence dynamics between major American and European stock markets, both during crisis periods and tranquility periods. Their evidence shows meaningful changes in connectedness and shock transmissions during the two periods analyzed; this is robust evidence of financial contagion between these two markets.

Neural networks are being widely used in economics and financial applications. ${ }^{2}$ The literature suggests numerous advantages that artificial neural networks (ANN) have over statistical methods. Among these advantages must ANN's capacity to learn be mentioned along with better model non-linear and complex relationships; also, after learning from the original initial inputs and their relationships, artificial neural networks can derive unseen relationships, even from unseen data. Finally, ANN does not impose restrictions on the input variables concerning, for example, the distribution of the series (Mahanta, 2017).

In terms of our object of study, it is important to stress that the U.S. economy and markets have a key role in the global financial architecture. According to the International Monetary Fund (n. d.), the American GDP (Gross Domestic Product) represented 25\% of the world GDP and the U.S. economy accounted for $21 \%$ and received $14 \%$ of total portfolio investments

1 Kendall's $\tau$ and Spearman's $\rho$, refers to correlation parameters.

2 The Artificial Neural Network approach has been pursued to enhance trading in the securities markets (Choudhury et al., 2014), to forecast performance of the economy (Feng \& Zhang, 2014), for stock price prediction (Hafezi et al., 2015), and to analyze credit risk (Grace \& Williams, 2016). 
in 2007. This partially explains the subprime crisis magnitude and its importance since the financial episode was centered on the U.S. housing market. This crisis caused widespread banking failures, massive downturns in asset markets, and eventually a worldwide recession. It is therefore of utmost importance to examine the relationship between the U.S. stock market and the world stock markets.

However, a simple relationship among the stock markets' indexed activities and co-movements is limited. We undertake a thorough view assessing which are the variables that explain changes in stock market dependence. Related studies include Poshakwale and Mandal (2017), who study economic and non-economic sources of stock return comovements of the Indian, U.S., UK, German, French, Canadian, and Japanese stock markets. Findings show that international interest rates, inflation uncertainty, and dividend yields are the main drivers of the asymmetric return co-movements. Ahmed et al. (2017) examine the importance of economic fundamentals in the transmission of international shocks to financial markets in emerging markets. The evidence shows that differences in economic fundamentals appeared to play a role in explaining the heterogeneous financial market responses during the global financial crisis of 2008, and the role of fundamentals appeared to progressively increase through the European crisis in 2011 and, subsequently, the 2013 taper tantrum.

Following these lines of research, this paper examines stock return comovements (dynamic dependence) between the U.S. (S\&P 500) and the World (MSCIW) markets during the period from 2000-2016, which includes episodes of financial calm and turmoil. ${ }^{3}$ Once dynamic dependence is estimated, we analyze if monetary variables (long and short-term interest rates, interest rates spread and exchange rates ${ }^{4}$ ) explain changes in this

3 The period of study was selected because this research is focused on the global financial crisis, an episode where at first time non-conventional monetary policy was displayed.

4 To estimate time-varying dependence between the U.S. and world stock returns, we employ daily closing data of Standard \& Poor's 500 Index and the Morgan Stanley Capital International World Index (MSCIW), from January 2000 to June 2016. Once the dynamic dependence is estimated, it is used as the dependent variable; and the explanatory variables are the following: 3-month US Treasury bill rate (domestic short-term rate), 3-month LIBOR 
relationship. Dependence is estimated employing a Dynamic Copula Approach. Additionally, we apply ANN analysis to determine whether monetary variables describe the dynamic relationship between the U.S. equity market and the global stock market.

Summing up, this research contributes to the financial literature in two ways. First, it proposes a relatively innovative and complementary methodology which overcomes the limitations of traditional approaches. Our twofold 1) the approach allows us to capture non-linearity, non-normality, skewness, and dynamic behavior in financial series. Additionally, 2) this article sheds some light on the nature of dynamic dependence between the U.S. and the world stock markets and on the incidence and importance of key monetary variables in this relationship of dependence, above all, during the recent COVID-19 crisis and in the face of the coordinated response of different governments and monetary authorities. The empirical evidence is of outmost importance in terms of monetary policy, asset allocation, risk management, and the creation of investment strategies.

The rest of this paper is organized as follows: Section II explains the methodology; Section III describes the data and presents the main empirical analysis and results; and conclusions follow in Section IV.

\section{Methodology}

Concretely, to estimate the time-varying relationship between the U.S stock market and the world stock market, this paper introduces a relatively innovative approach. First, an Archimedean Copula function is employed to measure the dependence. Dynamic behavior is incorporated through a rolling window calculation; dependence is measured daily, using windows with 251

(foreign short-term rate), 10-year Treasury bond (domestic long-term rate), UK 10-year bond yield (foreign long-term rate), 30-year U.S. rate (domestic long-term rate), UK 30-year bond yield (foreign long-term rate), Euro/USDollar and UKPound/USDollar (exchange rate), UK 10-year bond yield-10-year Treasury bond (long-term rate foreign-domestic spread), 3-month LIBOR-3-month T-bills (short-term rate foreign-domestic spread), 10-year Treasury bond3 months T-bills (long and short-term domestic spread), UK 10-year bond yield-3 months LIBOR (long and short-term foreign spread). Interest rates are modeled as change rate and prices (exchange rate and indexes) as price returns. 
days (about 8 months), according to the average business days of the year. This allows us to capture dynamic dependence.

Once the dynamic dependence series is generated, Artificial Neural Network Analysis is employed to test whether monetary variables determine changes in dynamic dependence. In other words, the monetary factors which drive contagion or interdependence effects between the U.S. stock market and the global stock market are calculated.

\section{A. Econometric Modeling}

Definition 1.1. A function $C:[0,1]^{n} \rightarrow[0,1]$ is a $n$-copula if it fulfills the following features:

1. $\forall u \in[0,1], C(1, \ldots, 1, u, 1, \ldots, 1)=u$

2. $\forall u_{i} \in[0,1], C\left(u_{1}, \ldots, u_{n}\right)=0$ if at least one of the $u_{i}^{\prime} s$ is equal to zero.

3. $C$ is defined, and n-growing (i.e., the $C$-volume of each box which vertices are in $\left.[0,1]^{n}\right)$ is positive.

A Copula is a multivariate distribution in the interval $[0,1]^{n}$ with uniform margins. In this case the Copula is the multivariate distribution function with a transformation to a univariate marginal (Korbicz, et al. 2020).

Definition 1.2. Sklar's Theorem (1959). Let $\mathrm{F}$ be a $n$-dimensional distribution function with continuous marginals $F_{1}, \ldots, F_{n}$, there is a unique $n$-copula $C:[0,1]^{n} \rightarrow[0,1]$ such that

$$
\left(x_{1}, \ldots, x_{n}\right)=C\left(F_{1}\left(x_{1}\right), \ldots, F_{n}\left(x_{n}\right)\right) .
$$

The copula combines marginals to form a multivariate distribution. This theorem provides a parametrization for the multivariate distribution. Given a $\mathrm{F}$ distribution with multivariate marginals $F_{1}, \ldots, F_{n}$, the function

$$
C\left(u_{1}, \ldots, u_{n}\right)=F\left(F_{1}^{-1}\left(u_{1}\right), \ldots, F_{n}^{-1}\left(u_{n}\right)\right)
$$

is a $n$-copula. This is the copula of the multivariate distribution $\mathrm{F}$. 
According the Sklar theorem, the n-dimensional density $f$ can be represented as follows:

$$
f\left(x_{1}, \ldots, x_{n}\right)=f\left(x_{1}\right) * \cdots * f\left(x_{n}\right) * c\left(F_{1}\left(x_{1}\right), \ldots, F_{n}\left(x_{n}\right)\right)
$$

where $c$ is the density of copula $C$. This result allows the selection of different margins and the dependence structure given by the copula to be used in the construction of a multivariate distribution. This contrasts with the usual procedure to generate a multivariate distribution because the restriction on the margins are usually of the same type (Zhi, Wang \& Xu, 2021).

Sklar theorem allows us to derive a copula for each multivariate distribution function. Despite the fact that there are many types of copulas, just some families are commonly used; among these families are the Archimedean copulas used in this paper.

Archimedean copula is chosen because of its advantages and benefits. Archimedean copulas allow modeling dependence in arbitrarily high dimensions with only one parameter, governing the strength of dependence (Grover, 2015). It is considered an advantage, as there are other approaches which provide a large number of parameters, making the analysis difficult. Among the Archimedean copulas, we estimate the Clayton copula because of its adequacy to describe negative skewness, which is an important feature of stock market return series (Nelsen, 1999).

As previously mentioned, closely following a previous paper by Sosa et al. (2015), our Copula approach applies rolling window estimation, using 251-day windows (about 8 months) according to the average business days of the year.

Definition 1.3 Archimedean Copula. A Bivariate distribution of this copula family can be represented as follows:

$$
C_{\alpha}\left(u_{1}, u_{2}\right)=\phi_{\alpha}^{-1}\left[\phi_{\alpha}\left(u_{1}\right)+\phi_{\alpha}\left(u_{2}\right)\right], \quad 0 \leq u_{1}, u_{2} \leq 1
$$

where $\phi_{\alpha}$ is convex and decreasing such as $\phi_{\alpha} \geq 0$. Function $\phi_{\alpha}$ is the generator of copula $C_{\alpha}$ and $\phi_{\alpha}^{-1}$ is the inverse of the generator, named Laplace transformed of a latent variable $\gamma$, which induces dependence $\alpha$. The selection 
of a generator gives as a result different types of Archimedean copula. In this document Clayton copula is employed (Yaméogo \& Barro, 2021).

Definition 1.4 Clayton Copula. The bivariate copula belonging to Clayton copula is defined as

$$
C_{\alpha}\left(u_{1}, u_{2}\right)=\left\{u_{1}^{1-\alpha}+u_{2}^{1-\alpha}-1\right\}^{\frac{1}{(1-\alpha)}}, \quad \alpha>1
$$

with its generator $\phi_{\alpha}(t)=t^{1-\alpha}-1$, and Laplace transformed $\phi_{\alpha}^{-1}(s)=$ $(1+s)^{\frac{1}{(1-\alpha)}}$

\section{B. Dependence measure via copulas}

Each of the multiple copula families is characterized by a parameter or parameter vector. This parameter measures the dependence among margins and is called dependence parameter $\theta$. In this case, bivariate copulas are estimated with a dependence parameter $\theta$. There is a relation between the dependence parameter and the concordance measure Tau de Kendall, which is addressed in the following section (Fenech \& Vosgha, 2019).

Let $X_{1}$ and $X_{2}$ be two random variables with marginals continuous distribution functions $F_{1}$ and $F_{2}$ and joint distribution function $F$. The traditional concept of dependence, Kendall's $\tau$, could be represented in terms of copula F. Kendall's $\tau$ is given by

$$
\tau\left(X_{1}, X_{2}\right)=4 \iint_{0}^{1} C\left(u_{1}, u_{2}\right) d C\left(u_{1}, u_{2}\right)-1 .
$$

The Kendall's $\tau$ is in function of the $X_{1}$ and $X_{2}$ copulas. In this study, there is a special interest in the Kendall rank correlation $\tau$.

To sum up, if $\left(X_{1}, X_{2}\right)$ have a bivariate Archimedean copula and arbitrary continuous marginals, the Kendall's $\tau$ is

$$
\tau=\frac{(\alpha-1)}{(\alpha+1)}
$$




\section{Copula parameters estimation}

There are several methodologies for estimating the parameters associated with copula. This paper employs maximum likelihood. Copula parameters can be obtained by maximizing its log-likelihood function, as explained below:

Let $C$ be a copula, such that,

$$
F\left(x_{1}, \ldots, x_{n}\right)=C\left(F_{1}\left(x_{1}\right), \ldots, F_{n}\left(x_{n}\right)\right)
$$

with density function,

$$
f\left(x_{1}, \ldots, x_{n}\right)=c\left(F_{1}\left(x_{1}\right), \ldots, F_{n}\left(x_{n}\right)\right) \prod_{j=1}^{n} f_{j}\left(x_{j}\right)
$$

Therefore, the maximum likelihood estimation mechanism can be defined as follows:

Let $C$ be $X$ an r.vi.i.d. vector with multivariate distribution function $F$ and continuous marginal distribution function $F_{1}, \ldots, F_{n}$; the log-likelihood function is defined below:

$$
l(\theta)=\sum_{j=1}^{n} \ln c\left(F_{1}\left(x_{j, 1}\right), \ldots, F_{n}\left(x_{j, n}\right)\right)+\sum_{j=1}^{n} \sum_{i=1}^{d} \ln f_{i}\left(x_{j, i}\right)
$$

where $\theta$ are the parameters for both marginal set and copula. Thus, given the marginal set and a copula, the log-likelihood function can be maximized obtaining the maximum likelihood estimator (Sosa et al., 2021).

$$
\widehat{\theta}_{M L E}=l(\theta) .
$$

\section{Dynamic copula estimation}

To analyze how the dependence between the U.S. and the world stock markets evolves during the period of study, a rolling window approach is proposed. Figure 1 shows this estimation process. For each 251 days (trading days in one year, approximately), a copula parameter is estimated. Once the 
first parameter is obtained ( $1^{\text {st }}$ window, from Day 1 to Day 251), the window is moved one day, capturing the following day's information. In this sense, the dependence measure, approached by a rolling window, allows us to analyze daily changes in the relationship between the two equity markets under study.

Figure 1. Daily 251-Day Rolling Window

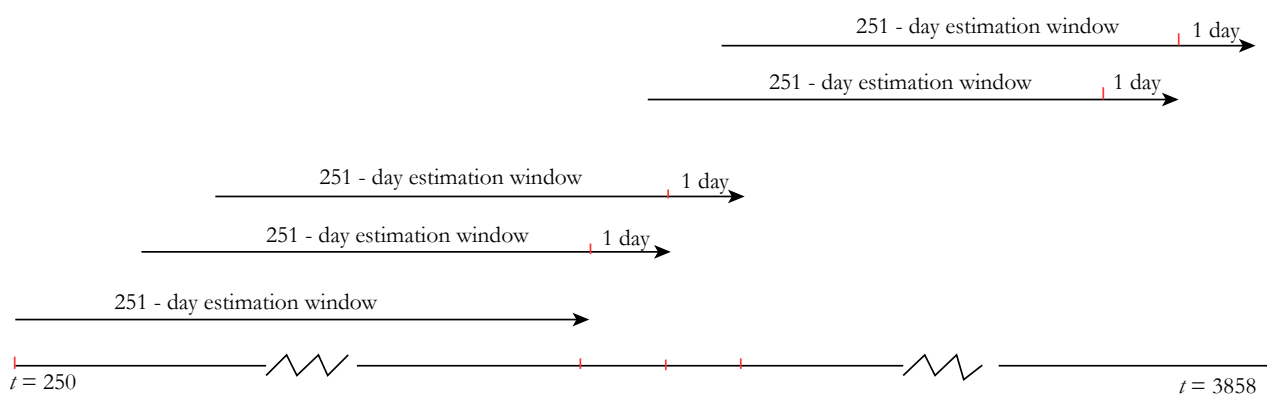

Source: own elaboration.

\section{E. Artificial Neural Network}

A neural network represents an important class of non-linear approximation and classification models (Fischer, 2015); it is an information processing paradigm inspired by biological nervous systems such as the brain to process information (Nunes da Silva et al., 2017). It is composed of many elementary computational units (neurons) working in unison to solve specific problems (Coakley \& Brown, 2000; Maind \& Wankar, 2014). Neural networks learn through experience, generalize from previous knowledge, and can make decisions.

The most common neural network consists of three types of layers: input layers, hidden layers, and output layers. There are various types of neural networks; for insatance, multilayer perceptron (MLP) ${ }^{5}$ is a neural network with one or more hidden layers. MLP is a feedforward Network, which means that it reacts to environmental changes to keep a certain state in the system. An MLP network allows the analysis of more complex patterns (Tsai \& Wu, 2008). In

5 Details of perceptron are presented by Popescu et al. (2012). 
multilayer networks, the predicted outputs for each training are estimated, and then it is calculated the difference between the target and the predicted value. Thus, error is reduced by the algorithm training (Tsai \& Wu, 2008).

The input layer is integrated by neurons which receive data from the environment. The hidden layers do not have a direct connection with the environment but receive data and information from the input layer. This layer is where the environment characteristics are estimated, modeled, and represented. Finally, the output layer provides the network result.

\section{F. ANN Training Process}

The ANN training process consists of modeling the hidden layers to represent the functional forms with data obtained in the input layer. Training is executed on a sub-sample $D=\left\{X^{(n)}, t^{(n)}\right\}, \mathrm{W}$ (weights) are adjusted on the input function, to minimize the error function, through the gradient descent method (Manurung et al., 2020).

$$
E_{D}(w)=\frac{1}{2} \sum n \sum i\left(\left(t_{i}^{(n)}-y_{i}\left(x^{(n)} ; w\right)\right)\right)^{2} .
$$

Minimization is based on continuous evaluation of the gradient $E_{D}$ with the chain rule, following the next steps:

1. Synaptic weights and initial thresholds are established

2. Bases are executed to obtain a network answer in front of the $r$ pattern

3. Those signs are interpreted as error signals associated to this process; these errors are estimated as

$$
\left(\sum_{k=1}^{s}\left(\sum_{j=1}^{0} W_{k j}^{\prime} Y_{j}^{r}-\theta_{k}\right) W_{k j}\right) \frac{\partial f\left(\sum_{i=1}^{n} W_{j i} X_{j}^{r}-\theta_{j}\right)}{\partial\left(\sum_{i=1}^{n} W_{j i} X_{j}^{r}-\theta_{j}\right)} .
$$

4. The total increment for every pattern, of thresholds and weights $\Delta W_{k j}^{\prime}$ and $\Delta W_{j i}^{\prime}$, is estimated.

5. Weights and thresholds are updated. 
6. The total error is estimated again in $t+1$. If this error is not satisfactory, in other words, if this error is different to the minimum absolute found by the gradient descent, it is interpreted as an error signal in the process and Step 3 is repeated until the minimal error is found.

In addition, for each of the hidden layers and output layers, an activation function is estimated by an algorithm. The activation function relates the weighted sum of layer units with unit values of the correct layer. This activation function is different for hidden layers and output layers (Liu, et al. 2019).

For hidden layers, the types of functions are: 1) the log-sigmoid form, $f(a)=\frac{1}{\left(1+e^{-a}\right)}$ and 2) the hyperbolic tangent tanh activation function

$f(a)=\tanh =\frac{e^{a}-e^{-a}}{e^{a}+e^{-a}}$. The activation functions for output layers are identity $=f(a)=a$ and softmax $=f(a)=\frac{\exp \left(a_{k}\right)}{\left(\sum_{j} \exp \left(a_{j}\right)\right)}$.

When the function has minimized the errors and found the activation functions, the process is concluded. To test the model, a separate sample is used to contrast predicting outputs with target outputs.

It is important to mention that the ANN separates data in three different subsets: training, testing, and reserve subsamples. The training subsample is used to run the model in the hidden layer, the testing subsample allows us to confirm the adequate learning process in terms of minimizing the function error, and the reserve subset is not considered in the two previous subsets; it is employed to verify the closeness between the estimated data by the ANN and real data to reduce bias in estimation (Paule-Vianez, et al., 2019).

\section{Empirical Evidence}

\section{A. Data}

To estimate time-varying dependence between the U.S. and world stock returns, we employ daily closing data of Standard \& Poor's 500 Index and the Morgan Stanley Capital International World Index (MSCIW), from January 2000 to June 2016. Once the dynamic dependence is estimated, it is used 
as the dependent variable; and the explanatory variables are the following: 3-month US Treasury bill rate (domestic short-term rate), 3-month LIBOR (foreign short-term rate), 10-year Treasury bond (domestic long-term rate), UK 10-year bond yield (foreign long-term rate), 30-year U.S. rate (domestic long-term rate), UK 30-year bond yield (foreign long-term rate), Euro/US Dollar and UK Pound/US Dollar (exchange rate), UK 10-year bond yield10-year Treasury bond (long-term rate foreign-domestic spread), 3-month LIBOR-3-month T-bills (short-term rate foreign-domestic spread), 10-year Treasury bond-3 months T-bills (long and short-term domestic spread), UK 10-year bond yield-3 months LIBOR (long and short-term foreign spread). Interest rates are modeled as change rate and prices (exchange rate and indexes) as price returns.

\section{B. Graphic analysis}

Figure 1 summarizes the behavior of both the U.S. stock prices and returns and the world prices and stock returns. MSCI and S\&P 500 experienced two important downturns in 2003 and 2008. These events could be related to the announcement of the Iraq invasion in 2003 and the beginning of the global financial crisis. The return series seems to show volatility clusters and asymmetry in 2001-2003, 2007-2009, 2011-2012, 2014-2015. All these represented financial turmoil episodes: the dot com, subprime, and sovereign debt crises. In this sense, apparently, the series presented similar behavior during instability periods, above all from 2007 to 2012. Dynamic copula analysis, applied in the following section, allows checking how alike the behaviors of two series are and whether there was contagion or interdependence between them.

Table 1 shows that the American stock market on average is more profitable and volatile than the global stock market. Both series are negatively skewed and show excessive kurtosis, which means their distribution is characterized by heavy tails and sharp peaks. The Jarque-Bera test reinforces the idea that series are not normally distributed. These features are consistent with the dynamic copula methodology proposed. 
Sosa, Bucio, and Ortiz: Dynamic Stock Dependence and Monetary Variables...

Figure 2. Prices and returns of MSCIW and SerP 500

S\&P 500

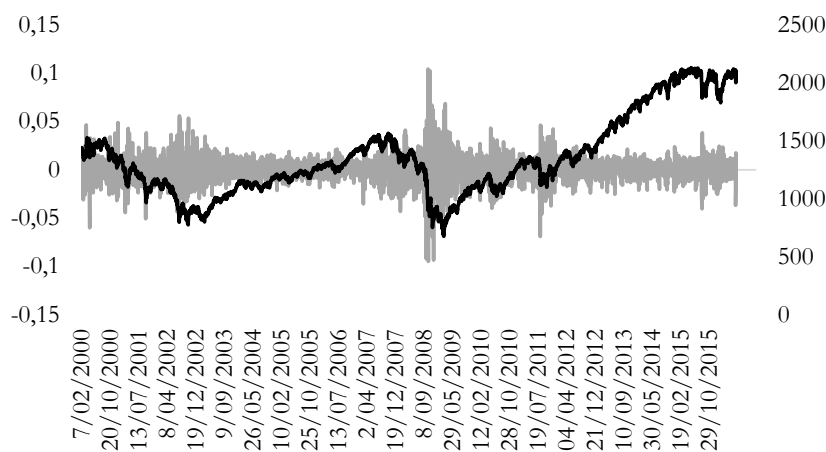

MSCIW

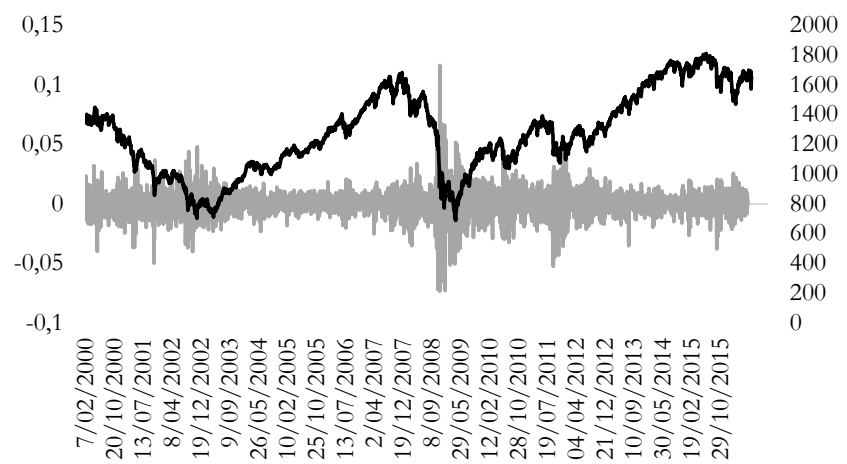

Source: own elaboration.

\section{Dynamic copula estimation}

As previously mentioned, to analyze dynamic dependence between the American and world share markets from January 2000 to June 2016, the dynamic copula approach is applied; results are shown in Figure 3. Copula estimation confirms that there is a high dependence during the whole period; it is on average 0.62 , reaching levels around 0.7 during long periods. According to McCluskey and Lalkhen (2007), a coefficient level of 0.7 shows high correlation between variables. This finding is consistent with interdependence term, which is defined as a high level of correlation between 
two markets across time; it suggests strong linkages between two markets (Forbes \& Rigobon, 2002) and can be explained due to the importance of the financial and economic activity of the U.S. in the world and because several relationships that this economy keeps with the rest of the countries, for example, through capital flows.

Table 1. Descriptive Statistics

\begin{tabular}{lcc}
\hline & MSCIW & S\&P 500 \\
\hline Mean & $4.23 \mathrm{E}-05$ & $7.10 \mathrm{E}-05$ \\
Maximum & 0.116287 & 0.104236 \\
Minimum & -0.073253 & -0.094695 \\
Std. Dev. & 0.010704 & 0.012704 \\
Skewness & -0.177987 & -0.151586 \\
Kurtosis & 13.76864 & 11.68694 \\
Jarque-Bera & 15899.55 & 10347.86 \\
\hline
\end{tabular}

Source: own elaboration with estimation results.

Figure 3. Copula results

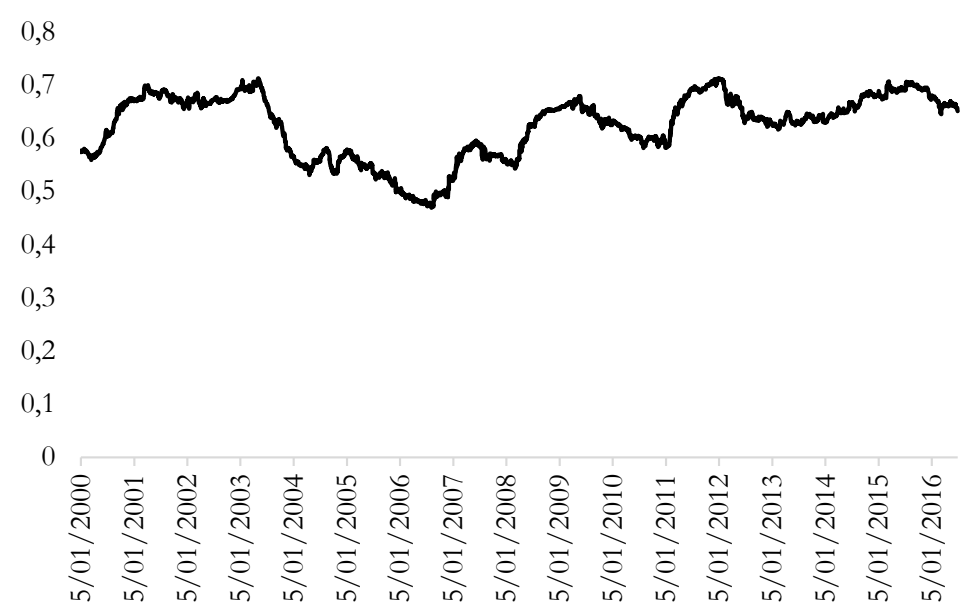

Source: own elaboration with estimation results. 
Sosa, Bucio, and Ortiz: Dynamic Stock Dependence and Monetary Variables...

Figure 4. Monetary variables

Panel A. Short-term rates

T Bills 3 months \%

Libor 3 months(\%)
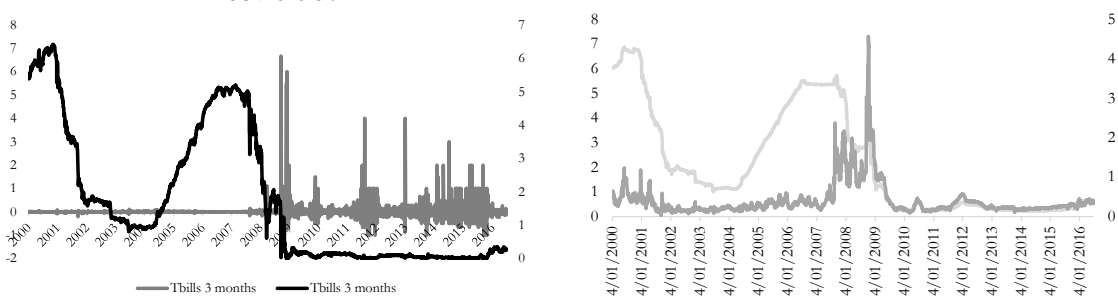

Panel B. long-term rates

US 10 years $(\%)$

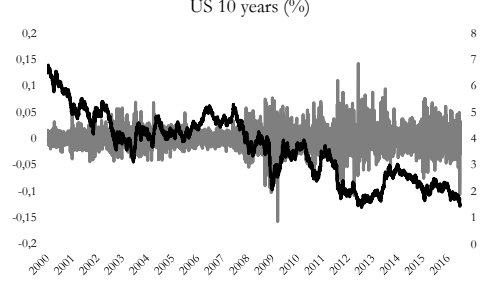

US 30 years $(\%)$

UK 10 years (\%)

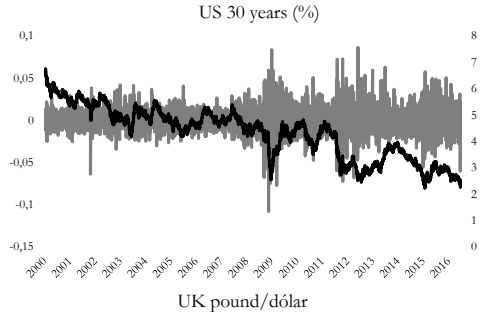

UK 30 years (\%)
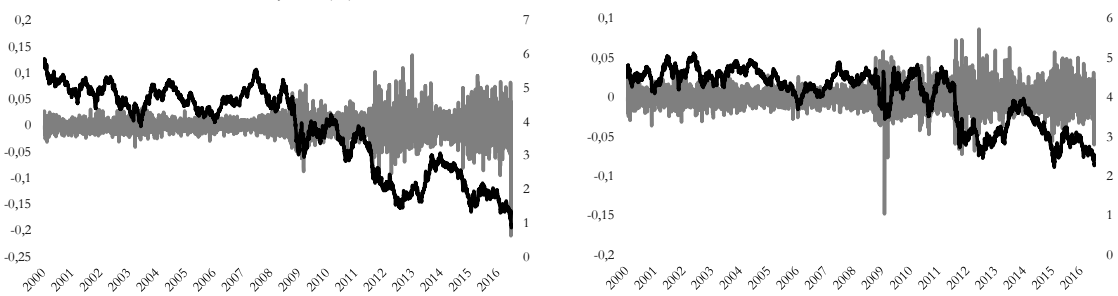

Panel C. Interest rate spread

Spread 10 Y UK-US

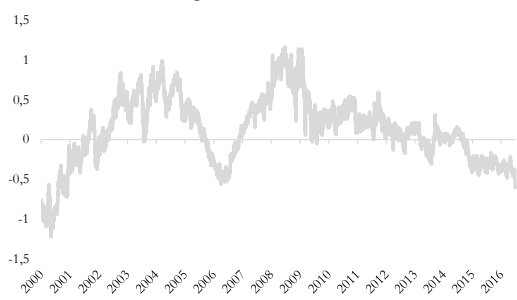

Spread 3 Months UK-US

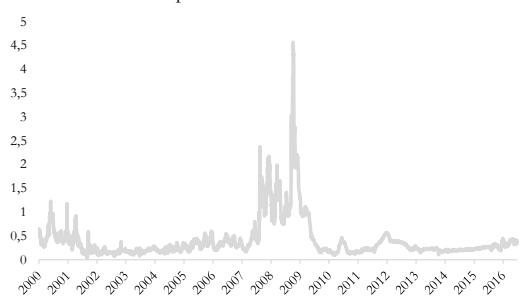


Panel D. Long- and short-term interest rates spread
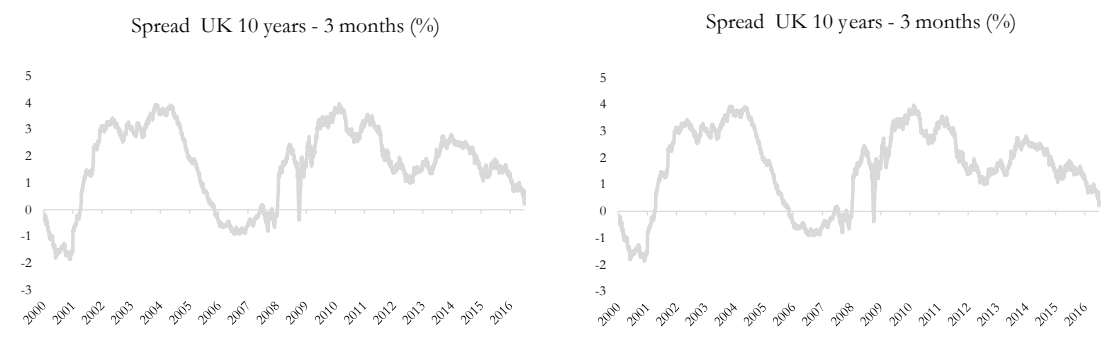

Panel E. Exchange rates
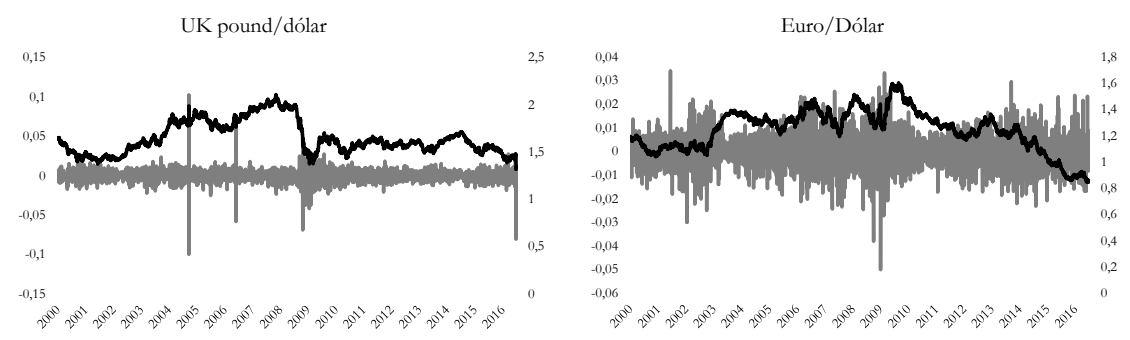

Source: own elaboration.

Once dynamic dependence is estimated, monetary variables are analyzed in Figure 4. It can be observed that 3-month T-bills and 3-month LIBOR rates exhibit a common behavior; it seems that LIBOR rate is a following indicator of T-bills. Both rates decreased from 2000-2004; the U.S. funds rate reached 1\% level in 2003, the lowest in 45 years. Between 2004 and 2006, the Federal Reserve Board raised interest rates 17 times, increasing them from 1 percent to 5.25 percent (Bianco, 2008). Finally, because of Quantitative Easing programs, the Federal Reserve and the Bank of England reduced the interest rate since 2008 with the purpose of alleviating financial market distress (Fawley \& Neely, 2013).

Short-term rate is a key economic and financial indicator, not just for the American economy, but for the rest of the world. U.S. monetary authorities manipulated this variable to attenuate instability and restart the economic activity. 
Long-term rates (10 years and 30 years) present a negative trend during the whole period; it may be explained by a monetary policy decision to stimulate economic activity. It is important to mention that these economic indicators have presented higher volatility since 2008.

Panel C shows the interest rate spread between the U.K. and the U.S., of long and short terms. The 10 -year spread presented an important growth from 2000 to 2004, probably because of the FED lowered funds rate; from August 2004 to January 2006, it exhibited a negative trend which reverted, reaching the highest level in August 2008. This indicator is stabilized and diminished less abruptly than in previous episodes (2008-2016).

In the 3-month spread, it can be observed that there are important changes during the dot com crisis period, above all, from August 2007 to July 2009. Changes in short-term rate spread can be explained because of the dramatic cuts to the Federal Reserve funds rate in comparison with the U. K. funds rate.

In Panel D, it can be observed that the long short-term rate spreads for the U.S. and the U. K. Both figures reflect similar change although UK rate changes are softer than U.S. variations. Similar to the 10-year spread (Panel C), the long short-term spreads presented an important fall associated with unconventional monetary policy application; the spread tended to zero from 2005 to 2007.

Panel E shows exchange rate evolution; the Euro/US Dollar rate indicator is more volatile than the Pound/US Dollar indicator. The highest variations in Pound/USD were in September 2004, June 2006, October 2008, and June 2016. Variations of 2004 and 2006 may be related to abrupt changes in the U.S. reference rate. October 2008 shift could be associated with Lehman Brothers bankruptcy, and June 2016 could be explained through the beginning of Brexit, when U.K. voters chose to leave the European Union. 


\section{Neural Network results}

Following the dynamic copula estimation, ${ }^{6}$ we apply a neural network i) to prove whether monetary variables can explain changes in dependence between the U.S. and world stock markets returns and ii) to know which of the variables under analysis are more important to describe co-movements between the American and Global stock markets.

The dependent variable is the dependence (measure via Copula Approach), and the explanatory variables are the following: short-term rates (3-month LIBOR and T-bills), long-term rates (10 and 30 years U.K. and U.S.), spread between LIBOR and T-bills short-term rates (3-month), spread between U.K. and U.S. long-term rates (10-year), spread between long and short-term rates in the U.S. (10-year-3 month U.S.), spread between long and short-term rates in the U.K. (10-year-3-month U.K.), and exchange rates (Euro/USD and Pound/USD).

Table 2 summarizes the network information; the left side shows the sample distribution: $72.3 \%$ is used to train the ANN, $20.8 \%$ is employed to test the network, and $6.9 \%$ is the reserve. On the right-side the ANN results and characteristics are presented. As previously mentioned, the multilayer perception model has one dependent variable (dynamic dependence) and 12 explanatory variables (monetary variables). There are eight units in the hidden layer, and its activation function is hyperbolic tangent. In the output layer, the change of scale method is standardized, the activation function is identity, and the error function is the square sum.

Testing the model means to know how good the model is to forecast values with provided information; a separate sample is used to contrast predicting outputs with target outputs. Figure 5 shows the results of this test; the estimated values are compared with the real outputs "copula", which are the dependence values estimated by the dependence measure. In the dispersion graph (left side), if the estimated and the real values were equal, this would be represented by a $45^{\circ}$ line. The comparison shows that the target

6 The dependent variable is estimated by measuring the dependence between the U.S. and the world stock markets; the copula approach is used to achieve it. This series is represented in Figure 3. 
and estimated outputs are not the same, but they are very similar. The line graph (right-side) reinforces this finding, the gray line represents the estimated output and the black one the real value; the difference is almost imperceptible

It can be observed that the difference between the predicting and the target outputs is not significant. This appreciation is complemented with the estimation of the average error, which is $0.049 \%{ }^{7}$ and the Mean Absolute Error (MAE), which is on average $0.014 \% .{ }^{8}$ This evidence shows that monetary variables are suitable to explain changes in dependence and, hence, to predict movements in this financial relationship.

Figure 5. Estimated Value vs Dynamic Copula
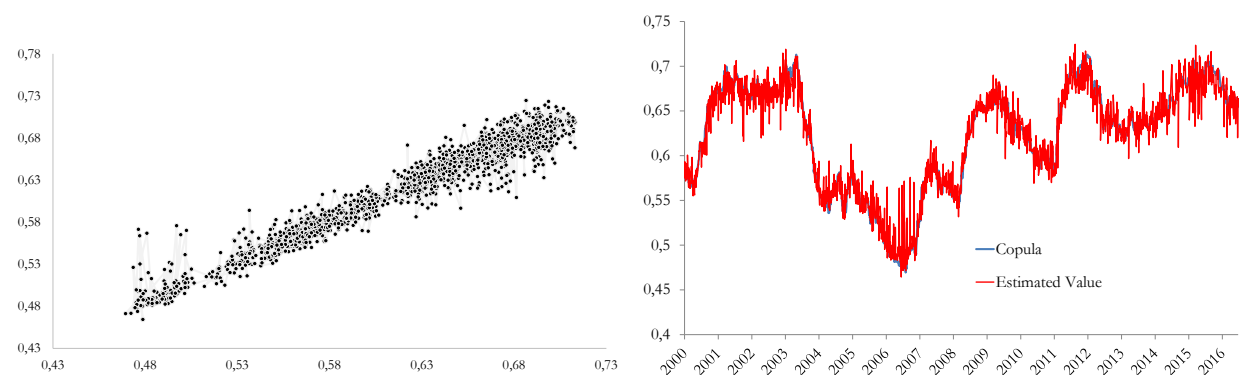

Source: own elaboration with estimation results.

ANN approach, contrary to econometric models, does not allow to observe what occurs inside of hidden layers, in terms of the coefficients obtained. However, ANN models allow the procurement of information related to the importance of the impact of independent variables on the dependent one. This analysis is known as the importance analysis of the variables 9 .

7 The average error is estimated as follows: (target output-predicted output) predicted output for each of the out-of-sample observations mathrm; afterwards, the average is obtained.

8 Mean Absolute Error = Target output-Predicted output.

9 The following function allows the measuring of the synaptic weights of the variables and its impact on the output (Montaño, 2002): $Q_{i k}=\frac{\sum_{j=1}^{L}\left(\frac{W_{i j} V_{j k}}{\sum_{r=1}^{N} W_{r j}}\right)}{\sum_{i=1}^{N}\left(\sum_{i=1}^{L}\left(\frac{W_{i j} V_{j k}}{\sum_{r=1}^{N} W_{r j}}\right)\right)}$ 
Table 2. ANN Information

\begin{tabular}{|c|c|c|c|}
\hline \multicolumn{4}{|c|}{ Sample Data } \\
\hline & & $\mathrm{N}$ & Percentage \\
\hline \multirow[t]{6}{*}{ Sample distribution } & Training & 1416 & $72.30 \%$ \\
\hline & Testing & 413 & $20.80 \%$ \\
\hline & Reserve & 136 & $6.90 \%$ \\
\hline & & 1966 & $100.00 \%$ \\
\hline & ded & 1890 & \\
\hline & & 3856 & \\
\hline \multirow[t]{12}{*}{ Input layer } & Factors & 1 & T Bills 3M \\
\hline & & 2 & US 10-year \\
\hline & & 3 & US 30-year \\
\hline & & 4 & LIBOR 3M \\
\hline & & 5 & UK 10-year \\
\hline & & 6 & UK 30-year \\
\hline & & 7 & Pound/USD \\
\hline & & 8 & Euro/USD \\
\hline & & 9 & 10-year UK-US \\
\hline & & 10 & 3M UK-US \\
\hline & & 11 & US $10 \mathrm{Y}-3 \mathrm{M}$ \\
\hline & & 12 & UK $10 \mathrm{Y}-3 \mathrm{M}$ \\
\hline \multirow[t]{3}{*}{ Hidden layer } & \multicolumn{2}{|c|}{ Number of units } & 20428 \\
\hline & \multicolumn{2}{|c|}{ Number of hidden layers } & 1 \\
\hline & \multicolumn{2}{|c|}{ Activation Function } & Hyperbolic tangent \\
\hline \multirow[t]{5}{*}{ Output layer } & Dependent variables & 1 & Dynamic copula \\
\hline & \multicolumn{2}{|c|}{ Number of units } & 1 \\
\hline & \multicolumn{2}{|c|}{ Change of scale method } & Standardized \\
\hline & \multicolumn{2}{|c|}{ Activation Function } & Identity \\
\hline & \multicolumn{2}{|c|}{ Error Function } & Square Sum \\
\hline
\end{tabular}

Source: own elaboration with estimation results.

In this sense, once it is proved that monetary variables describe variations in American and global stock markets co-movements, we analyze what the most important monetary variables in this process are. To reach that purpose, 
the importance of the variable analysis is employed; ${ }^{10}$ This variable measures how much the predicted value changes for different values of each of the independent variables.

Table 3 presents the results of normalized importance analysis. It shows that the short-term spread between 3-month LIBOR rate and 3-month Treasury bill rate (3M LIBOR-T-bills) is the most important factor that explains changes in dynamic dependence between the American and the global stock market. The short-term spread is considered an extremely important variable due to its systematic nature; it influences the expected returns of the rest of the assets of a given economy. In addition, changes in government bond yields have an impact on asset allocation, generating portfolio rebalancing. These variables influence the dynamic co-movements between stock markets.

Table 3. Normalized Importance Results

\begin{tabular}{lcc}
\hline Factor & Importance & Normalized Importance \\
\hline 3M LIBOR-T Bills & .113 & $100.0 \%$ \\
TBills 3M & .112 & $98.6 \%$ \\
LIBOR 3M & .079 & $70.1 \%$ \\
Euro/USD & .079 & $70.1 \%$ \\
US 10Y-3M & .079 & $69.4 \%$ \\
US 10-year & .078 & $69.0 \%$ \\
Pound/USD & .078 & $69.0 \%$ \\
UK-US 10-year & .078 & $69.0 \%$ \\
US 30-year & .076 & $67.6 \%$ \\
UK 10 Y-3M & .076 & $67.4 \%$ \\
UK 30-year & .076 & $67.2 \%$ \\
UK 10-year & .075 & $66.4 \%$ \\
\hline
\end{tabular}

Source: own elaboration with estimation results.

10 The normalized importance is estimated by dividing the importance value of each variable by the highest value of themselves; the result is multiplied by 100 . Hence, the highest value divided by itself is equal to 100 . 
The short-term spread is followed by the 3-month T-Bill rate (T-bills $3 \mathrm{M}$ ) and 3-month LIBOR rate (LIBOR 3M), respectively. Factors with lower relevance are the foreign long-term rates (UK 10 years and UK 30 years). These results reinforce previous empirical and theoretical evidence about the importance of short-term interest rate in portfolio decisions and capital flows (Bruno \& Shin, 2015; Rapach et al., 2016, 2016; Poshakwale \& Mandal, 2017; Bodenstein et al., 2017).

It is important to mention that the EUR/USD exchange rate is also a key variable influencing dynamic stock market relationships. It could be explained in two ways: i) it is closely related to the interest rate, changes in the shortterm rate affect investors' attractiveness and appetite for local markets, and ii) changes in the currency also affect the real return on portfolio investment. On the other hand, from a macroeconomic point of view, the exchange rate increases/decreases the costs of imported goods and decreases/increases the price of exports, affecting the competitiveness of local companies.

\section{Conclusions}

This research analyzed the dynamic dependence between the U.S. and the global stock market returns and tested if monetary variables described changes in this relationship, during the January 2000 - June 2016 period. To attain these objectives, an innovative twofold methodology was implemented. Firstly, to examine dependence between the American and world stock market a dynamic copula approach was applied. Secondly, to determine whether monetary variables explain changes in co-movements between those two markets, a neural network approach was employed.

Copula results evidence that there is a strong relation between the U.S. stock market and the global equity market. This relation during the whole period averaged is 0.62 , nearing 0.7 during long periods. According to the financial literature, this can be considered a case of an interdependence phenomenon between these two equity markets. This high dependence can be attributed to the American large market share in the financial and economic global processes. 
Sosa, Bucio, and Ortiz: Dynamic Stock Dependence and Monetary Variables...

Neural network model findings showed that monetary variables suitably describe changes in stock markets co-movements. The estimated model seems to be very accurate with an average error of $0.049 \%$ between the target outputs and the predicted ones. In reference to the importance of monetary variables, the short-term interest rate spread was the most important variable which explained changes in stock dependence, followed by the 3-month Tbills rate and 3-month LIBOR rate.

Our evidence is important to monetary authorities and to portfolio and risk managers. It reinforces theoretical and empirical findings about the incidence of short-term interest rates in stock dependence since these monetary variables affect asset allocation and portfolio decisions. In this sense, changes in short-term interest rates impact capital in-and-out flows, having significant effects in stock markets through higher volatility and lower mean returns of share prices. At the same time, it influences stock markets' dependence changes by promoting the creation of contagion and interdependence phenomena.

It is important to broaden research about stock dependence concerning which variables explain changes in stock market relationships. Hence, future research should include other economic and non-economic variables, analyzing other countries and periods and, finally, examining the importance of monetary policy shocks during calm and crisis periods on economic activity and financial operations. Empirically, further studies might include other approaches such as causality analysis, graph theory, or dynamic conditional correlation.

\section{References}

Ahmed, S., Coulibaly, B., \& Zlate, A. (2017). International financial spillovers to Emerging Market Economies: How Important Are Economic Fundamentals? Journal of International Money and Finance, 76, 133-152. http://doi.org/10.1016/j.jimonfin.2017.05.001

Aloui, R., Aïssa, M. S. B., \& Nguyen, D. K. (2011). Global Financial Crisis, Extreme Interdependences, and Contagion Effects: The Role 
of Economic Structure? Journal of Banking \& Finance, 35(1), 130-141. https://doi.org/10.1016/j.jbankfin.2010.07.021

Baur, D. (2003). Testing for Contagion-Mean and Volatility Contagion. Journal of Multinational Financial Management, 13(4), 405-422. https://doi.org/10.1016/S1042-444X(03)00018-5

Ben Amar, A., Hachicha, N., \& Halouani, N. (2021). Is There a Shift Contagion among Stock Markets During the COVID-19 Crisis? Further insights from TYDL Causality Test. International Review of Applied Economics, 35(2), 188-209. https://doi.org/10.1080/0269 2171.2020.1853685

BenMin, I., \& Ben Saïda, A. (2019). Financial Contagion Across Major Stock Markets: A Study During Crisis Episodes. The North American Journal of Economics and Finance, 48, 187-201. https://doi.org/10.1016/j.na jef.2019.02.005

Bianco, K. M. (2008). The Subprime Lending Crisis: causes and Effects of The Mortgage Meltdown. CCH, Wolters Kluwer Law \& Business.

Bodenstein, M., Erceg, C. J., \& Guerrieri, L. (2017). The Effects of Foreign Shocks when Interest Rates Are at Zero. Canadian Journal of Economics, 50(3), 660-684. https://doi.org/10.1111/caje.12274

Boyer, B. H., Gibson, M. S., \& Loretan, M. (1997). Pitfalls in Tests for Changes in Correlations, vol. 597. Board of Governors of the Federal Reserve System.

Bruno, V., \& Shin, H. S. (2015). Capital flows and the risk-taking channel of Monetary Policy. Journal of Monetary Economics, 71, 119-132. https: //doi.org/10.1016/j.jmoneco.2014.11.011

Cevik, S., \& Ozturkkal, B. (2020). Contagion of Fear: Is the Impact of COVID19 on Sovereign Risk Really Indiscriminate? [IMF Working Paper Series No. 2020/263]. https://www.imf.org/en/Publications/WP/Issues/20 20/11/25/Contagion-of-Fear-Is-the-Impact-of-COVID-19-on-Sove reign-Risk-Really-Indiscriminate- 49903 
Chen, W., Wei, Y., Zhang, B., \& Yu, J. (2014). Quantitative Measurement of The Contagion Effect between U.S. and Chinese Stock Market During the Financial Crisis. Physica A: Statistical Mechanics and its Applications, 410, 550-560. https://doi.org/10.1016/j.physa.2014 .05 .060

Chiang, T. C., Jeon, B. N., \& Li, H. (2007). Dynamic Correlation Analysis of Financial Contagion: Evidence from Asian Markets. Journal of International Money and finance, 26(7), 1206-1228. https://doi.org/ 10.1016/j.jimonfin.2007.06.005

Cho, D., \& Choi, K. (2015). Time-varying Co-movements and Contagion Effects in Asian Sovereign CDS Markets. Journal of East Asian Economic Review, 19(4), 357-379. http://doi.org/10.11644/KIEP.JEAI.2015.19 .4 .301

Choudhury, S., Ghosh, S., Bhattacharya, A., Fernandes, K. J., \& Tiwari, M. K. (2014). A Real Time Clustering and SVM Based Price-volatility Prediction for Optimal Trading Strategy. Neurocomputing, 131, 419426. https://doi.org/10.1016/j.neucom.2013.10.002

Coakley, J. R. \& Brown, C. E. (2000). Artificial Neural Networks in Accounting and Finance: Modeling Issues. International Journal of Intelligent Systems in Accounting, Finance Management, 9, 119-144. http://doi.org/10.1002/1099-1174(200006)9:23.0.CO;2-Y

Fawley, B. W., \& Neely, C. J. (2013). Four Stories of Quantitative Easing. Federal Reserve Bank of St. Louis Review, 95(1), 51-88. http: //doi.org/10.20955/r.95.51-88

Fenech, J. P., \& Vosgha, H. (2019). Oil Price and Gulf Corporation Council Stock Indices: New Evidence from Time-varying Copula Models. Economic Modelling, 77, 81-91. https://doi.org/10.1016/j. econmod.2018.09.009

Feng, L., \& Zhang, J. (2014). Application of Artificial Neural Networks in Tendency Forecasting of Economic Growth. Economic Modelling, 40, 76-80. https://doi.org/10.1016/j.econmod.2014.03.024 
Fischer, M. (2015). Neural Networks. A Class of Flexible Non-linear Models for Regression and Classification. In: C. Karlsson, M. Anderson \& T. Norman (eds.) Handbook of Research Methods and Applications in Economic Geography (Chapter 8, pp. 172-192). Edward Elgar Editors.

Forbes, K. J., \& Rigobon, R. (2002). No Contagion, Only Interdependence: Measuring Stock Market Comovements. The Journal of Finance, 57(5), 2223-2261. https://doi.org/10.1111/0022-1082.00494

Glover, R. E., van Schalkwyk, M. C., Akl, E. A., Kristjannson, E., Lotfi, T., Petkovic, J., ... \& Welch, V. (2020). A framework for identifying and mitigating the equity harms of COVID-19 policy interventions. Journal of clinical epidemiology, 128, 35-48. https://dx.doi.org/10.1016\%2Fj.j clinepi.2020.06.004

Gong, Y., Li, K. X., Chen, S. L., \& Shi, W. (2020). Contagion Risk Between the Shipping Freight and Stock Markets: Evidence from The Recent US-China Trade War. Transportation Research Part E: Logistics and Transportation Review, 136, 101900. http://dx.doi.org/10.1016/j.t re.2020.101900

Grace, A. M., \& Williams, S. O. (2016). Comparative Analysis of Neural Network and Fuzzy Logic Techniques in Credit Risk Evaluation. International Journal of Intelligent Information Technologies, 12(1), 47-62. https://doi.org/10.4018/IJIIT.2016010103

Grover, V. (2015). Identifying Dependence Structure among Equities in Indian Markets Using Copulas [MPRA Paper 66302]. University Library of Munich. https://ideas.repec.org/s/pra/mprapa.html

Hafezi, R., Shahrabi, J., \& Hadavandi, E. (2015). A Bat-neural Network Multi-agent System (BNNMAS) for Stock Price Prediction: Case study of DAX Stock Price. Applied Soft Computing, 29, 196-210. https: //doi.org/10.1016/j.asoc.2014.12.028

International Monetary Fund. (n. d.). IMF Data. Coordinated Portfolio Investment Survey (CPIS), 2007. "Geographic Breakdown of Total Portfolio Investment Assets: TOTAL PORTFOLIO INVESTMENT 
Sosa, Bucio, and Ortiz: Dynamic Stock Dependence and Monetary Variables...

(Derived from Creditor Data)". Accessed on January $9^{\text {th }}$ of 2018. https: //data.imf.org/cpis

Kenourgios, D., Samitas, A., \& Paltalidis, N. (2011). Financial Crises and Stock Market Contagion in A Multivariate Time-varying Asymmetric Framework. Journal of International Financial Markets, Institutions and Money, 21(1), 92-106. https://doi.org/10.1016/j.intfin.2010.08.005

Korbicz, J., Bidyuk, P., Kuznietsova, N., Kroptya, A., Terentiev, O., \& Prosiankina-Zharova, T. (2020). Multivariate Distribution Model for Financial Risks Management. In ICST (pp. 416-429). http://ceur-ws. org/Vol-2711/paper32.pdf

Liu, S., Borovykh, A., Grzelak, L. A., \& Oosterlee, C. W. (2019). A Neural Network-based Framework for Financial Model Calibration. Journal of Mathematics in Industry, 9(9), 1-28. https://doi.org/10.1186/s13362 -019-0066-7

Loretan, M., \& English, W. B. (2000). Evaluating Correlation Breakdowns During Periods of Market Volatility [International Finance Working Paper, 658]. Board of Governors of the Federal Reserve System. https: //ideas.repec.org/p/fip/fedgif/658.html

Maind, S.B. \& Wankar, P. (2014). Basic of Artificial Neural Network. International Journal on Recent and Innovation Trends in Computing and Communication, 2, 96-100. https://doi.org/10.1016/S0731-7085 (99)00272-1

Maneejuk, P., \& Yamaka, W. (2019). Predicting Contagion from the US Financial Crisis to International Stock Markets Using Dynamic Copula with Google Trends. Mathematics, 7(11), 1032. https://doi.org/10.339 0/math7111032

Manurung, A. H., Natasha, C., \& Budiharto, W. (2020). Modelling shares choice to enter in a portfolio using artificial neural networks (ANN). Journal of Big Data, 7(17), 1-9. https://doi.org/10.1186/s4 0537-020-00294-w 
McCluskey, A., \& Lalkhen, A. G. (2007). Statistics II: Central tendency and spread of data. Continuing Education in Anaesthesia, Critical Care \& Pain, 7(4), 127-130. https://doi.org/10.1093/bjaceaccp/mkm020

Mahanta, J. (2017, July $10^{\text {th }}$ ). Introduction to Neural Networks, Advantages and Applications [Blog]. Online Data Science School. https://towardsd atascience.com/introduction-to-neural-networks-advantages-and-appl ications-96851bd1a207

Mohti, W., Dionísio, A., Ferreira, P. \& Vieir, I. (2019). Contagion of the Subprime Financial Crisis on Frontier Stock Markets: A Copula Analysis. Economies, 7(15) https://doi.org/10.3390/economies7010015

Montaño, J. (2002). Redes neuronales artificiales aplicadas al análisis de datos [Doctoral Thesis, Universitat de les Illes Balears]. https://www.tesisenr ed.net/bitstream/handle/10803/9441/tjjmm1 de1.pdf? sequence $=1$

Nelsen, R. B. (1999). An Introduction to Copulas. In Lecture Notes in Statistics (vol. 139). Springer.

Ortmans, A., \& Tripier, F. (2020). COVID-Induced Sovereign Risk in the Euro Area: When Did the ECB Stop the Contagion? [Working Paper No. 202011]. CEPII Research Center. https://ideas.repec.org/p/cii/cepidt/202011.html

Paule-Vianez, J., Gutiérrez-Fernández, M., \& Coca-Pérez, J. L. (2019). Prediction of Financial Distress in the Spanish Banking System: An Application using Artificial Neural Networks. Applied Economic Analysis, 28 (82). https://doi.org/10.1108/AEA-10-2019-0039

Popescu, M-C., Balas, V.E., Perescu-Popescu, L., \& Mastorakis N. (2012). Multilayer Perceptron and Neural Networks. WSEAS Transaction on Circuits and Systems, 8(7), 579-588. https://www.researchgate.net/pub lication/228340819_Multilayer_perceptron_and_neural_networks

Poshakwale, S. S., \& Mandal, A. (2017). Sources of Time Varying Return Comovements during Different Economic Regimes: Evidence from the Emerging Indian Equity Market. Review of Quantitative Finance and Accounting, 48, 859-892. https://doi.org/10.1007/s11156-016-0580-2 
Sosa, Bucio, and Ortiz: Dynamic Stock Dependence and Monetary Variables...

Rapach, D. E., Ringgenberg, M. C., \& Zhou, G. (2016). Short Interest and Aggregate Stock Returns. Journal of Financial Economics, 121(1), 46-65. https://doi.org/10.1016/j.jfineco.2016.03.004

Rodriguez, J. C. (2007). Measuring Financial Contagion: A Copula Approach. Journal of Empirical finance, 14(3), 401-423. https://doi. org/10.1016/j.jempfin.2006.07.002

Shell, A. (2018, August $\left.15^{\text {th }}\right)$. Turkey currency crisis: What it means for stock market and 401(k)s. U.S.A Today. https://www.usatoday.com/story $/ \mathrm{m}$ oney/2018/08/15/turkey-lira-crisis-impact-401-k/984949002/

Sklar, A. (1959). Fonctions de répartition á n dimensions et leurs marges. Publications de l'Institut Statistique de l'Université de Paris, 8, 229-231.

Sosa, M., Bucio, C., \& Cabello, A. (2015). Mercados de capitales del bloque Bric+ México: dependencia estimada con un enfoque de cópulas. Investigación Administrativa, 44(115). http://www.scielo.org .mx/scielo.php?script=sci_arttext\&pid=S2448-76782015000100005

Sosa, M., Bucio, C., \& Cabello, A. (2021) Contagion Effect in the BRIC+ M block: A MS-Copula Approach. Panorama Económico, 16 (33), 51-74. http://panoramaeconomico.mx/ojs/index.php/PE/article/view/62

Syllignakis, M. N., \& Kouretas, G. P. (2011). Dynamic Correlation Analysis of Financial Contagion: Evidence from the Central and Eastern European Markets. International Review of Economics \& Finance, 20(4), 717-732. https://doi.org/10.1016/j.iref.2011.01.006

Tachibana, M. (2018). Relationship between stock and currency markets conditional on the US stock returns: A vine copula approach. Journal of Multinational Financial Management, 46, 75-106. https://doi.org/10 .1016/j.mulfin.2018.05.001

Tsai, C. F., \& Wu, J. W. (2008). Using Neural Network Ensembles for Bankruptcy Prediction and Credit Scoring. Expert systems with applications, 34(4), 2639-2649. https://doi.org/10.1016/j.eswa.200 7.05.019 
Yaméogo, W., \& Barro, D. (2021). Modeling the Dependence of Losses of a Financial Portfolio Using Nested Archimedean Copulas. International Journal of Mathematics and Mathematical Sciences, 2021. https://doi.or $\mathrm{g} / 10.1155 / 2021 / 4651044$

Zhi, B., Wang, X., \& Xu, F. (2021). Portfolio Optimization for Inventory Financing: Copula-based Approaches. Computers \& Operations Research, 136, 105481. https://doi.org/10.1016/j.cor.2021.105481 